Information Management and Business Review

Vol. 1, No. 2, pp. 79-87, Dec 2010

\title{
Private Sector in Indian Healthcare Delivery: Consumer Perspective and Government Policies to promote private Sector
}

\author{
*Utkarsh Shah, Ragini Mohanty \\ Prin. L. N. Welingkar Institute of Management Development and Research \\ Matunga, Mumbai, \\ *utkarsh.shah@welingkar.org
}

\begin{abstract}
This research paper attempts to collate literature from various sources, in an attempt to answer three pertinent questions related to healthcare in India. Firstly, what is it meant by 'private sector' in healthcare delivery system of India, secondly how has the private sector evolved over the decades and what has been the role of the government in propelling the growth. Finally, the paper tries to highlight some of the factors that have promoted the growth of private sector in India with specific reference to quality of medical care. The paper explicitly indicates that the deficiencies in the public health delivery system of India, was the key to growth of private infrastructure in healthcare. The shift of hospital industry for 'welfare orientation' to 'business orientation' was marked by the advent of corporate hospitals, supported by various policy level initiatives made by the government. Today, there are over 20 international healthcare brands in India with several corporate hospitals. However, a large section of the 'private healthcare delivery segment' is scattered and quality of medical care continues to remain a matter of concern. This paper tracks the various government initiatives to promote private investment in healthcare and attempts to explore the reasons for preference of the private sector. Surprisingly, in contrast to contemporary belief, quality of medical care doesn't seem to be the leading cause for preference of the private sector. Except for a few select corporate and trust hospitals, quality of medical care in private sector seems to be poor and at times compromised.
\end{abstract}

Keywords: Private sector, Indian Healthcare, Government policies, delivery system, consumer perspective

\section{Prelude}

India is rapidly transforming with persistent augmentation of the physical infrastructure and technological capabilities across all sectors. Health Sector is also witnessing significant transformation with the liberalization of the market and increasing involvement of the private sector. For over three decades after independence, health sector was dominated by the public sector, with the contribution of the private sector limited to ambulatory care services. Over the past few decades, Indian Healthcare has witnessed a growth in the number of corporate and private hospitals, providing specialized and tertiary level of medical care. Empirical evidence has projected the current availability of hospital beds in India at approximately 1.1 beds per 1000 people, which in other words implies that there is one bed for every 971 people (FICCI, 2007). This bed to population ratio is very poor when compared to its counterpart developing nations like China, Korea and Thailand. It is estimated that to reach a modest bed to population ratio of 2 per 1000 person, India will require over 17.5 lakh additional hospital beds, which would collectively require an investment of over INR. 3, 70,000 crores (Ernest and Young, 2008) over the next ten years.

Indian healthcare is at a critical juncture, as it focuses on pertinent issues of consumerism, cost effectiveness and quality. Indian healthcare is annually growing at the rate of $15 \%$, which is faster than most of the other service sectors. The importance of good quality of healthcare infrastructure is reiterated by the government's commitment to offer a five year tax holiday, for private providers, establishing multi-specialty medical care facilities ( Finance Act, 2008) , anywhere in India, excepting eight major metros and urban agglomerations. A skewed distribution of medical facilities, between the Urban and Rural India, has resulted in little access to "good quality and specialized" medical care 
services, for the rural population. In the recent years, the changing population dynamics and the demographic trends, and steadily increasing incidence of non-communicable diseases like cardiovascular disorders, cancers, diabetes, etc have reiterated the need for different strategic interventions, to arrest the morbidity and mortality, associated with the conditions (NMCH, 2005).

Inevitably, Indian healthcare infrastructure needs to be apt to tackle the dual disease burden, with better technological capabilities and interventions, superior quality of medical care infrastructure, specialized and trained medical personal, proportionate investment in healthcare facilities and pertinent need for medical innovations to be supported by clinical research, for "evidence based medical treatment". International healthcare market, also steadily impacts Indian market, as it creates strong and lucrative opportunities for medical tourism. Exponentially rising cost of medical care in the United States, long waiting time for patients in socialistic health systems like the United Kingdom and inadequate medical care infrastructure in the Middle East and Africa, attract foreign patients to India in search of international quality of medical care at a fraction of the cost (RNCOS, 2009). The objectives of this are

1. Understanding the connotation of 'private sector in the healthcare delivery system' in India

2. Tracking the progress of the 'private sector' in India over the last two decades

3. Evaluating the role of Governments and policies in promoting the growth of the private sector

4. Analyzing the perception of the consumers, with specific reference to private sector

5. Ascertaining the role of 'quality in medical care' in promoting the growth of private sector

\section{Private Sector in Indian Healthcare Delivery System}

In Economics, private sector represents a part of the economy, which is operated by an individual or a group with the underlying objective of maximizing profits. A private sector institution is not operated or under the control of the State. Third Sector or Not-for-Profit sector, on the other hand, is operated by voluntary or community organization, with the objective of providing assistance to the poor and underprivileged sections of the society and thereby contribute to social welfare and equity. While trying to understand the connotation of 'private sector' in the Indian health service delivery sector, it is important to appreciate, that segmentation of the Indian healthcare system can't be made purely on the basis of the organizational incorporation (i.e. a for profit or a trust). Though the incorporation of an organization plays a critical role in determining the philosophy and objectives of the organization, it doesn't take into account certain considerations of professional management or orientation towards generating surplus. This kind of segregation undermines the importance of maximizing returns for not-for-profit organizations, for whom generating surplus plays a crucial role in ensuring sustainability and funds for infrastructural up gradations to provide superior quality of medical care services and cater to the need of the poor and underprivileged, by providing specialized services, at affordable cost.

It is for this reason, that several research studies conducted in this domain have always considered trust and charitable institutions are a part of the 'private sector'. As per some experts (Saxena, 2005 and Yap, 2008), tertiary care 'charitable' hospitals are at the apex of the healthcare delivery matrix providing specialized services. It is critical for charitable institutions to focus on 'profits' to sustain superior quality of services. This paper hence considers both not-for-profit institutions and private corporate hospitals will be herewith considered as a part of the Indian Private Sector. Post independence, public sector dominated the institutional delivery of medical care, while private sector dominated provision of ambulatory care services with several clinics and out patient settings. However, the gross insufficiencies in the public healthcare delivery system, acted as a driver to the growth of private sector institutions in the country (Nadkarni, 2010). In the initial stage of growth of the private sector, the focus was on compensating for the deficiencies of accessibility and availability in the public sector. The thrust, to growth of private sector hospitals, was the enforcement of neoliberal reforms enforced by World Bank and other international financing institutions in the 1990s, which forced the governments of developing nations to reduce public expenditure on social sectors including healthcare (Jilani, Azhar, Jilani \& Siddiqui, 2009). Complying with the conditionalities 
resulted in removal of price control and subsidizes by the state, trade liberation which in turn made imports of advanced medical equipments and technologies easier and promoting privatization and disinvestment across all sectors.

The reduced subsidies on medical care services and government's withdrawal from social sector resulted in market segmentation, which in turn resulted in an increased demand for quality medical care services by the upper and middle class segments in India. This factor made it attractive for private investors to operate profitable healthcare operations (Chakravarti, 2009), which resulted in increased private investment in healthcare. Multiple policy level changes propelled the growth of Indian private sector. Several hospitals were set up, under the banner of trusts and charitable institutions to cater to healthcare services. However, the turning point in Indian healthcare service delivery came with the establishment of the first 'corporate hospital' by Apollo Hospital Enterprise limited, in 1983 (Crisil Research, 2009). Ever since then Apollo Hospital Enterprise Ltd, has seen a tremendous growth with over 7500 hospital beds under its banner across 25 cities in India. Concurrently several other corporate hospitals were established across India including Escort Group, Wocharkdt Group of Hospitals and Fortis Healthcare (ILO, 2009).

\section{Methodology}

This paper attempts to track the growth of private sector, using secondary data analysis, and attempts to provide insights into the policy level changes promulgating the growth of the private sector. Further, this paper attempts to understand consumer perception about private sector and understanding the role of quality in healthcare delivery system. This study attempts to collate secondary data and literature available to provide relevant answers for the specific objectives defined herewith. This study reviews various research studies conducted between 1990s and 2010 along with comprehensive analysis of official government data available through various governmental agencies.

\section{Government Policies to Support the Growth of Private Sector}

In its attempt to promote private sector to cater to the healthcare needs of the burgeoning population base, the government took several measures to enhance investments in the private sector. Some of these decisions included,

1. A paradigm shift at policy level resulted in market segmentation, whereby government resources were to be used only for the deserving section of the society (NHP, 2002), while the affording population was expected to purchase medical care services from the private sector.

2. As per industry experts over $50 \%$ medical devices and equipments are imported (NIPER, 2010). Most of the equipments have to be purchased in foreign exchange, in a medical equipment market which is highly fragmented. This puts a considerable strain on hospital resources (Bhat, 2006). Further with rapid technological advances, medical equipment technology tends to become obsolete. In order to benefit the private sector, the government has consistently worked towards reducing import duty on medical equipment and technology. Recent budgets have reduced the customs duty of medical devices to a standard slab of 5\%, with a countervailing duty (CVD) of 4 per cent, for all medical equipments and devices. On the other hand parts or accessories of equipments and essential devices such as assistive devices, rehabilitation aids, etc are completely exempted from CVD (Union Budget 2010-11).

3. Similarly, to facilitate financial flexibility to healthcare institutions, the GOI increased the depreciation rates for essential equipments and consumables from $25 \%$ to $40 \%$. This in turn allows considerable amount of tax savings while computing the tax returns for the hospitals and healthcare institutions (Jain, 2006).

4. The government relaxed the procedures to attract Non Resident Indian doctors from the United States and United Kingdom, to return to India, which further boosted the growth of the private sector (Baru, 1998). 
5. In 2000, $100 \%$ Foreign Direct Investment in the hospital sector was permitted by the Reserve Bank of India along with additional benefits for Private Equity funding to promote healthcare infrastructure in India (Express Healthcare, 2010). These policies and the booming healthcare market in India have resulted in an investment of US\$379 million in 2007 which is about 6.8 percent of the total private equity (PE) investment of US\$ 5.93 billion (ILO, 2009).

6. The affordability for medical care increased with advent of several private sector healthcare insurance companies, post liberalization (Ahuja, 2004). The introduction of Third Party Administration, under the IRDA Regulation, 2001, increased focus on managed care (NCMH, 2005), which allowed cash-less service payments. Further, with the introduction of the Rastriya Swasth Bima Yojana, in 2008, a government insurance scheme, for underprivileged and economically backward sections, the affordability of BPL population for quality medical care services also increased.

7. Hospitals and Healthcare Institutions were conferred with Infrastructure Status in the Union Budget 2002-03, which made long term capital and loan cheaper for most of the private healthcare Institutions (ITA, 1961). Similarly the subsequent Union Budget of 2003-04 conferred an Industry status to hospitals and provided for benefits to financial institutions providing long term capital for hospital projects

8. Medical tourism was also given a thrust with the introduction of Medical Visa (M Visa) and Attendant Visa (MX Visa) mid 2005 (The Telegraph, 2005). A medical visa can be granted for a period of one year with as many as four multiple entries allowed. This promoted the growth of medical tourism which was estimated to have generated revenue of $\$ 600$ million in 2006 with over 0.5 million international health travelers visiting India during the same year (Gautam, 2008). Estimates are suggestive a $\$ 100$ billion industry by 2012 , provided the Indian healthcare infrastructure is upgraded to accept the opportunity (TOI, 2010).

9. In order to promote private healthcare infrastructure across India, the government provided for $100 \%$ income tax exemption for a period of five years, for newly established hospitals, from the date of commencement, if it is a 100 bed hospital and is located outside the eight urban agglomerations (Finance Act, 2008).

In addition, various state governments designed special packages to promote private investment in the creation of healthcare infrastructure and medical colleges across the country. The benefits include land allocation on subsidized rates, partial or complete wavier on stamp duty, electricity duty, conversion duty, etc (GOR, 2006). As per reports (Zee news, 2010), central government is also exploring options to operate medical colleges in certain regions on Public Private Partnership module.

\section{Population Dynamics and Proliferation of Private Sector}

In addition to the changing governmental policies, changing dynamics of the Indian population also facilitated the growth of the private sector, in the domain of healthcare

1. With changing life style patterns and industrialization, an increased incidence of non communicable diseases was observed over the past few decades. With dual disease burden (NMCH, 2009); there is an increasing demand for specialized medical care services. With government focusing on communicable disease and RCH program under NRHM, the lack of specialized care in public sector has further promulgated the growth of private sector

2. Change in the demographic profile of the nation has been suggestive of a middle class segment of 40-50 million, which has further triggered the demand for quality medical care services (Bhat, 1999). The figure below gives as estimate of the changing population dynamics. 

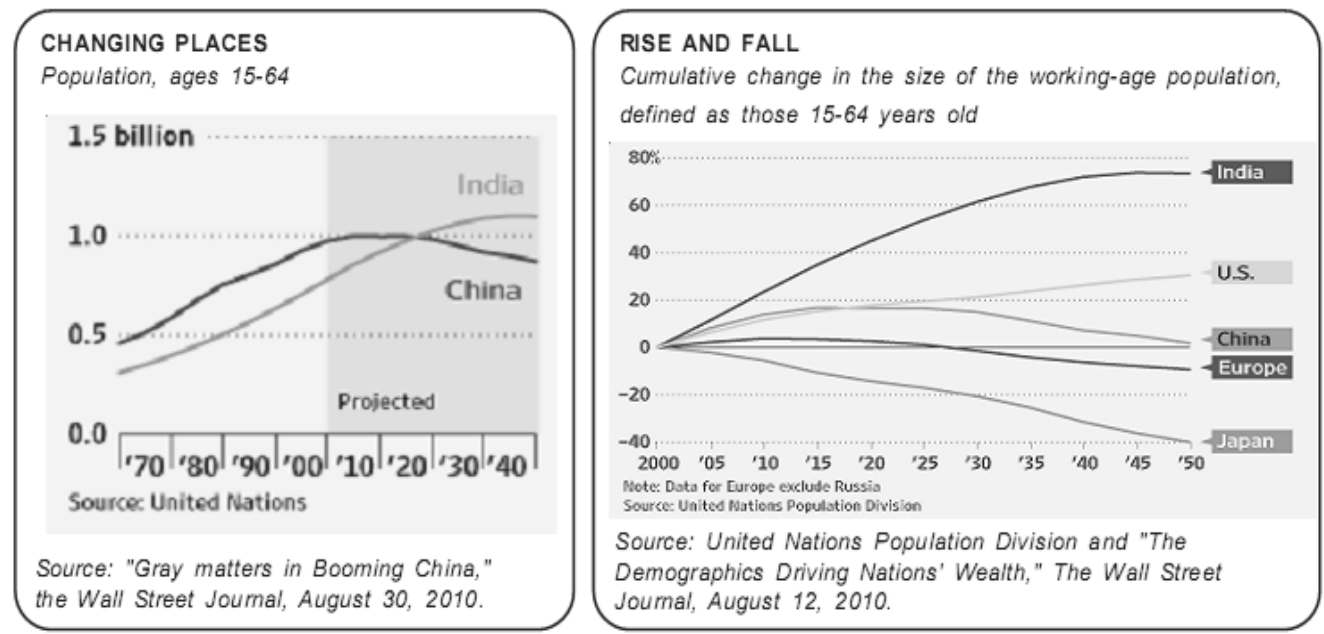

3. Higher portion of working population has propelled economic growth which in turn has further enhanced the affordability for medical care services (Economic Survey, 2007). As per estimates India will continue to have a GDP in excess of 6\% up to 2020 (Goldman Sachs, 2010).

4. With increasing level of educational attainment, booming Information technology and globalization, there is an overall increase in awareness about quality medical care services, which in turn has increased the demand for superior quality care at affordable prices.

\section{Consumer Perception of Private Sector: A Driver to Growth of Private Healthcare in India}

Empirical evidence has been suggestive of failure of public sector as one of the prime reasons for growth of the private sector in India (Chatterjee, 2008). As per estimates, hospitalization rates in private sector in urban and rural India are higher at $62 \%$ and $58 \%$ respectively (NSSO, 2006). Initial literature review has indicated that, in contrast to contemporary belief, quality of care is not the primary reason for utilization of private medical care services. This section attempts to review some of the studies to explain the behavior of the consumers and ascertain the reasons for preference of private sector. In a study to understand health seeking behavior of semi-urban population (Patel, Trivedi, et al, 2010), it was observed that $62 \%$ of the households preferred private healthcare facility. The reasons for avoiding government facility, though the services were free of cost included long waiting time, facility located at a distance, inadequate facilities, unclean premises, harsh behavior of the staff and low faith in government doctors. Among those preferring public sector hospitals, the leading reasons include free availability services (73.33\%) and close location of facilities $(68.33 \%)$. Interestingly, quality of medical care is not considered to be the criterion for selection of public or private sector facilities.

In another study conducted the city of Mumbai (Dilip \& Duggal, 2004), reasons for preference of private sector facility included proximity, quality of care and convenient timing. Affordability was a leading factor for selection of public healthcare facility. However on internal comparison of the data elicited that, $64.5 \%$ of users of private sector hospitals considered them affordable, while only $10.8 \%$ of the users of public healthcare facilities, considered public sector hospitals affordable. Another study (Pinto \& Udwadia, 2010) cited reasons like poor quality with a general lack of trust in government services, lack of attention offered to patients, long waits, poor hygiene, suspected quality of drugs and lack of privacy, for non preference of public sector hospital. Only a nominal portion (3\%) considered free services as a reason for preference of public sector. Similarly, another study (Chirumle, Gupte, 1997) reiterated the role of affordability, quality of medical care and availability of medical services, as critical in selection of public or private healthcare institutions, across five different states in India. 
Secondary data analysis has indicated that the strength of the private sector includes accessibility and availability of medical care services compared to the public sector, which has for long focused only on affordability. Though, affordability is a critical factor, it non congruence with the other two parameters which influence health seeking behavior, has overall promulgated the growth of private sector. With private sector omnipresent across urban and rural India, it continues to be preferred compared to the public sector (NCMH, 2004). Further, as per reports (NCMH, 2005) the cost of care in private sector is about 2.2 to 24.3 times higher but still it continues to be preferred, indicating the affordability is secondary to accessibility and availability.

\section{Quality and Private Healthcare Services}

'Quality' as defined by ISO 9000 Standards is a relative concept and if the inherent characteristic of a service meets the requirements of the customer, it can be rated as high quality .This implies that there are certain subjective and certain objective criterions, which define quality. In a service industry, like healthcare, experience of the patient plays a crucial role in rating and assessment of quality of medical care services. Quality in healthcare (Gyani, 2010) may comprise of newer technology, newer and effective medication, higher staff to patient ratios, affordability, efficiency and effectiveness of healthcare delivery. Private sector contributes to $68 \%$ of all hospitals and $37 \%$ of total beds in the country (NCMH, 2004). However large sections (about 95\%) of these facilities are 120 bed units, operated by an Individual Doctor or a group of doctors (PCI, 2006). Smaller private hospitals have limited infrastructure and equipment technology compared to the larger corporate hospitals, the quality of care remains questionable in the private sector, though empirical evidence is suggestive that it is better compared to public sector, in most cases. As per a study (Jain, 2006) a large number of private hospitals continue to have very low asset value indicative of limited medical technology and inferior quality of staff, yet they were considered better equipped compared to the public sector hospitals. In a study, across eight districts in India, it was observed that medical technology and quality of care, in private sector was superior compared to the public sector (NMCH, 2005).A comprehensive literature review has been indicative of the overwhelming preference of the private sector due to several reasons including shortfall of medicines, equipment and technology (Mahal, Srivastava \& Sanan, 2000 and Naylor, Jha, Woods \& Shariff, 1999), again indicative of poor quality of care in the public sector.

However, quality of care should not be considered as a differential factor for selection of private medical facilities. As per another study (Nadraj \& Duggal, 1996 and Nandraj, Khot \& Menon, 1999) conducted in Maharasthra, a large volume of medical professionals are either not qualified or don't have appropriate licenses to practice medicine, which in turn resulted in sub-standard quality of medical care. Several initiatives and efforts were made to standardize and improvement quality of care in medical facilities. In the first attempt, the Bureau of Indian Standards specified standards for hospitals of various sizes ranging from 30-250 beds. Further, the National Institute of Health and Family Welfare (NIHFW) specified rules for 50 bed institutions. However, as health is a State subject, the approval of respective state governments was required for streamlining implementation of various rules and regulations to enforce quality in medical care delivery. This resulted in a fragmentation of the industry with no unitary system to control quality standards across the entire country. Though these interventions had little impact on the quality of medical care across India, it resulted in the creation of National Accreditation Board for Hospitals and Healthcare Providers (NABH), as a national level accreditation structure. This accreditation system encompasses a wide gamut of areas including physical infrastructure, infection control standards, medical equipment technology, security, etc. Further, this accreditation system also reviews the clinical competence of the hospital to deliver the services within its scope. Though the implementation of NABH is in its preliminary stage, this intervention has defined the roadmap for future quality initiatives in the domain of healthcare delivery system. In addition, the approval of the Clinical Establishment Act, 2010 is also been designed to mandate certain provisions in private medical care facilities and is to be launched phase-wise across India (CEA, 2010). 
The efforts of the government are underway to design a National Health Bill (NHB, 2009), which focuses on patient rights while seeking medical care services. Though not directly related to provision of quality of medical care, the document attempts to enforce certain quality standards for patient care. In a study conducted to understand patient perception in quality of care in corporate hospitals (Yap, 2008), it was observed that in the surveyed set of 16 hospitals, the general satisfaction and technological capacity were rated high. Further interpersonal communication, interaction with the doctor and accessibility and convenience of treatment were also rated well. However, in reference to financial aspects, the hospitals were rated fairly poorly due to various issues like overshooting of hospital bills. This clearly indicates that with $29 \%$ of the population belonging to the lower income category, quality of medical care will continue to remain secondary to affordability, especially in private settings.

\section{Conclusion}

Indian healthcare infrastructure has evolved over the past six decades after the Indian independence. The role of private sector has been critical in the provision of medical care services. Though public sector provisions dominated healthcare delivery for the first few decades, economic and political changes over the past few decades, propelled, the growth of private sector, which is now poised to grow substantially. Other factors which have aided the Private sector in dominating the Indian healthcare delivery market include changing consumer perception, increasing awareness about quality of medical care, greater penetration of insurance, increased purchasing power, changing demographic structure, etc. Though, the debate over the 'righteousness' in the change in orientation in the Indian healthcare system continues (Nadkarni, 2010), various government policy initiatives are directed towards enhancing private sector investment in healthcare.

Private sector, itself has undergone tremendous changes over the decades. The advent of corporate culture in healthcare delivery has been observed in the past two decades, as healthcare was viewed as a profitable venture. Professional management of healthcare institutions, to generate profits or surplus also gained considerable momentum over the past two decades. Recent innovations include focus on ambulatory and retail healthcare, designed to focus on non communicable diseases. Inherent factors like improved efficiency, better quality, greater reliability and transparency has also aided in the growth of private sector in healthcare. With the incorporation of medical professionals under the Consumer Protection Act, 1986, there was increased realization of the importance of quality in provision of medical care services. With various initiatives of the Quality Council of India, efforts are underway to promote standardization of medical care services and enhance quality of medical care provided by the private sector. Private sector holds to key to improving healthcare delivery in India. However, as private sector continues to explore the opportunities, a tradeoff between 'social welfare' and 'business orientation' is critical. Further quality needs to standardize in a highly fragmented healthcare delivery system of India.

\section{References}

Ahuja, R. (2004), Health Insurance for the Poor in India, Working Paper No. 123, Indian Council for Research on International Economic Relations.

Baru, V. R. (1998), Private Healthcare in India: Social Characteristics and Trends, Sage Publications, New Delhi.

Jain, B. (2006), Financial Performance of Private Sector Hospitals in India: Some further evidence, Research and Publications, IIM-Ahmadabad.

Bhat, R. (1999). "Strengthening Emergency Care through the Provision of Ambulance in Public Health Facilities: Economic Issues and Policy Implementation Guidelines," IIMA Working Papers, WP1999-07-03.

Bhat, R. (2006), Financial Health of Private Sector Hospitals in India, IIMA Working Papers, WP2006-01-01 Research and Publication Department.

CAG, (2001), Review on Assessment of Private Hospitals and Nursing Homes: Review on Audit assessments of select sectors, Report of the CAG on Union Government (retrieved from (http://www.cag.gov.in/reports/d_taxes/2002_book2/index.).

CEA, 2010, Clinical Establishment Act, Ministry of Health and Family Welfare.

Chakravarti, I. (2009), Draft National Health Bill: Health Reforms for market not for People, Liberation (retrieved from www.cpiml.org/liberation/year_2009/dec_09/feature.html). 
Chatterjee, P. (2008), Factors that Frasterate growth of Private Health Sector in India (retrieved from medind.nic.in/haa/t08/i1/haat08i1p5.pdf).

Chirmule, G. (1997), Factors Affecting Health seeking and Utilization of Curative Health Care, Bharatiya Agro Industries Foundation, Pune.

Crisil Research (2009), Independent Equity Research- Apollo Hospital Enterprise Pvt Ltd, (retrieved from www.apollohospitals.com).

Dilip, T. R. \& Duggal, R. (2004), Unmet Need for Public Healthcare Services in Mumbai, India, Asia-Pacific Population Journal, 19(2): 27-40.

Economic Survey, (2006), Government of India

Ernst and Young, (2008), Fostering Quality Healthcare for All, FICCI Conference August 7-8, Federation House, New Delhi.

Express Healthcare, 2010, Quantum Leap in FDI, December Issue.

FICCI, 2007, Opportunities in Healthcare: Destination India, Ernst and Young Report.

$\begin{array}{llllll}\text { Finance Act, } & 2008, & \text { Section } & 80 & 11(\mathrm{c}) & \text { (retrieved }\end{array}$ http://www.taxindiaonline.com/RC2/union_budget/finance_act/finance_act_08/index.htm).

Gautam, V. (2008), Healthcare Tourism Opportunities in India, Export-Import Bank of India, Quest Publications.

Goldman Sachs, (2010) Dreaming with BRIC's: The path to 2050 (retrieved from http://www2.goldmansachs.com/ideas/brics/book/99-dreaming.pdf.

GOR, (2006), Policy to Promote Investment in Healthcare Facilities, Department of Medical Education, Government of Rajasthan.

Gyani, J. G. (2010), Hospital accreditation in India- Standardizing healthcare (retrieved from http://www.asianhhm.com/Knowledge_bank/articles/healthcare_accreditations_india.htm).

ILO, (2009), Indian Health Sector, Industry Report (retrieved from www.indialawoffices.com/industry_reports.php).

ITA, (1961), Section 10 (23G) of the Income Tax Act, 1961.

Jilani, A., Azhar, G., Jilani, N. \& Siddiqui, A. (2009). Private providers of Healthcare in India: A policy analysis. The Internet Journal of Third World Medicine, 8(1).

Mahal, A., Srivastava, D. \& Sanan, D. (2000), Decentralization, Democratization and Public Sector Delivery of Services: Evidence from Rural India, National Council of Applied Economic Research.

Nadkarni, S. (2010), Healthcare system is an industry, Management of the Sick Healthcare System, Vora Medical Publications, 1st Edition.

Nandraj, S. and Duggal, R. (1996), Physical standards in private health sector, Radical Journal of Health, 2 (2/3): 141-84.

Nandraj, S., Khot, A. \& Menon, S. (1999), Accreditation of Hospitals: Breaking Boundaries in Healthcare, CEHAT, Research Center of Anusandhan Trust.

Naylor, C. D., Jha, P., Woods, J. \& Shariff, A. (1999), A Fine Balance: Some options for Private and Public Healthcare in Urban India, World Bank, Human Development Network.

NCMH, (2004), National Commission of Macroeconomics and Health Report.

NCMH, (2005), Financing and Delivery of Healthcare Services in India, Healthcare Financing and Social Protection and Health Insurance in India (retrieved from http://www.whoindia.org/EN/Section102/Section201_377.htm).

NHB, (2009), Draft of the National Health Bill, Working Document.

NHP, (1983), National Health Policy Document Extract.

NHP, (2002), Section 1.2 (iv) and Section 2.2.3.

NIPER, (2010), Report of the National Institute of Pharmaceutical Education and Research, Ahmedabad (retrieved from http://www.dancewithshadows.com/pillscribe/medical-devices-market-in-india-to-reach17-billion-by-2010-niper/).

NMCH, (2005), Disease Burden in India: Estimations and Causal Analysis, Background papers, World Health Organization, India (retrieved from www.whoindia.org).

$\mathrm{NMCH},(2009)$, Estimates and Causal Analysis, Background papers- Burden of Disease in India.

NSSO, (2006), Sample Survey, 60th Round.

Patel P. B., Trivedi K. N., Nayak S. N., \& Patel P. (2010). Health seeking behavior of peri-urban community of Chandkheda. National Journal of Community Medicine, 1(1): 35-36.

PCI, 2006, Private Participation in Family Welfare Services, Planning Commission of India (retrieved from www.planningcommission.gov.in).

Pinto, L. M. \& Udwadia, Z. F. (2010), Private patient perceptions about a public program: what do private Indian Tuberculosis patients really feel about directly observed treatment, BMC Public Health, 10:356.

RNCOS, (2009), Opportunities in Medical Travel in India, Industry Report.

Saxena, M. (2005), Utilization of the private sector in Healthcare in India, South Asian Journal of Preventive Cardiology, 9(1), Jan-Mar (retrieved from www.sajpc.org). 
The Telegraph, (2005), Medical Visa make Debut, Kolkata, July, 9 (retrieved from http://www.telegraphindia.com/1050709/asp/frontpage/story_4969103.asp).

TOI, (2010), Medical Tourism to become USD 100 billion Industry by 2012: Report (retrieved from http://timesofindia.indiatimes.com/business/international-business).

Yap, C. (2008), Emergence of corporate hospitals in metropolises in India: Viable partnerships with Singapore, Institute of South Asian Studies, Internship program (retrieved from www.isas.nus.edu.sg).

Zee News, (2010), PPP colleges to promote medical education (retrieved from http://www.zeenews.com/news674996.html). 